\title{
LOS ARCHIVOS ECONOMICOS EN EUROPA Y EN ESPAÑA
}

\author{
TERESA TORTELLA CASARES \\ Archivo Histórico del Banco de España
}

\section{Introducción}

El Gobierno debe atender al pronto remedio de todos los archivos de la nación: tiempo es ya de que se procure la conservación de esos preciosos monumentos, que son sin disputa la fuente más pura de la verdadera historia. Nosotros desearíamos que todas las secretarías del despacho tratasen de uniformar este importante ramo, de la manera que lo ha emprendido ya el ministro de Gracia y Justicia en el notable decreto de 5 de noviembre de 1847 y posteriores resoluciones. Créese en Madrid una junta superior directiva de archivos por cada Ministerio, fórmense otras subalternas en la capital de provincia y de distrito para que inspeccionen los archivos establecidos y propongan los medios de mejorarlos: de esta manera y sin gravar los presupuestos podrá conseguirse el objetivo apetecido, y los estudiosos verán colmados sus deseos. Ojalá que esta justa censura sea un motivo para que se lleve a efecto lo que con tan buenos resultados se ha practicado ya en otras naciones de Europa, principalmente en Francia e Inglaterra.

Estas palabras, tomadas del estudio que sobre Madrid hace Pascual Madoz en su Diccionario Geográfico Histórico (1), resultan vigentes aún hoy día, quizá no aplicadas a los archivos públicos en los que se ha conseguido en gran medida lo que proponía Madoz, pero sí son absolutamente válidas para los archivos privados de nuestro país.

Efectivamente, existe un gran retraso en España en materia de archivos privados $\mathrm{y}$, dentro de éstos, en archivos de empresas o, de un modo más amplio, en archivos privados con fondos para la Historia Económica.

Apenas se ha emprendido en nuestro país, hasta fechas muy recientes, ninguna acción encaminada a salvaguardar, conservar o posibilitar el acceso en los fondos de archivos privados $\mathrm{y}$, más específicamente, en los de bancos y empresas.

(1) Pascual Madoz, Diccionario Geográfico Estadístico Histórico de España $y$ sus posesiones de Ultramar, $\mathrm{X}$, p. 831 . 
Hay, por supuesto, algunos casos de archivos económicos antiguos, de empresas ya desaparecidas, que han sido recogidos en archivos públicos, como, por ejemplo, el conocido Archivo del banquero Simón Ruiz, que tuvo un establecimiento de Banca en Medina del Campo (Valladolid), en el siglo xvi, hoy en el Archivo Histórico-Provincial Universitario de Valladolid y del que hay ya publicados numerosos trabajos (2). También el archivo del Consulado de Cádiz, con documentaciónn que data del siglo xvi, se conserva desde 1958 en el Archivo General de Indias (3); y el archivo de la Casa de Osuna, con documentación importante de carácter económico, fue adquirido por el Archivo Histórico Nacional en el año 1920. En cuanto a casos de épocas más recientes, documentos de alguna empresa nacional como EN. PETROL (Empresa Nacional del Petróleo) o de CEPSA (Compañía Espanola de Petróleos, S. A.), la mayor empresa privada de refino de España, están recogidos en el Archivo General de la Administración de Alcalá de Henares. Del mismo modo, parte de los fondos de RENFE o de las compañías antecesoras de ésta, procedentes de algunos ministerios, como, por ejemplo, Obras Públicas y Asuntos Exteriores, han ingresado también en el citado archivo de Alcalá. Pero estos casos y algún otro, más bien aislados, son la excepción. Es un hecho que hay, por una parte, una falta de espacio y de personal en los archivos públicos, $y$, por otra, muchas veces una falta de información en las entidades privadas acerca de la posibilidad de ingresar sus fondos en los archivos del Estado.

Situación de los archivos económicos en algunos países europeos

Esta situación ciertamente precaria de los archivos económicos contrasta con la que nos ofrecen estos mismos archivos en Europa en general y en algunos países en particular.

En Europa puede decirse que quizá debido a la influencia de algunos organismos oficiales, pero también gracias a iniciativas de las propias entidades privadas, el panorama se nos presenta bastante distinto.

Existe a nivel internacional un organismo, no gubernamental, patrocinado y subvencionado en parte por UNESCO, pero que opera con gran independencia, llamado Consejo Internacional de Archivos (C.I.A.). Fue creado en

(2) Entre otros, Henri LAPEYRE, Une famille de marchands: Les Ruiz. El Archivo Ruiz: veinte años después; José M." González Ferrando, "Los libros de cuentas de la familia Ruiz, mercaderes-banqueros de Medina del Campo (15511606)".

(3) Antonia Heredu HerRern, Archivo General de Indias. Inventarios de los fondos de Consulados. 
el año 1950, después de una serie de tentativas que se habían venido preparando desde el año 1910, en una primera reunión celebrada en Bruselas para tratar de trabajar en cuestiones archivísticas a nivel internacional (4).

Los cometidos del C.I.A. son establecer, mantener y estrechar relaciones entre archiveros de todos los países y entre cualquier institución u organismo cuyas actividades tiendan a la conservación, organización o administración de los archivos, así como facilitar la accesibilidad a éstos y favorecer la conservación y defensa de la documentación. Para ello organiza un Congreso Internacional cada cuatro años, publica una revista anual, Archivum, y coopera con otras instituciones para apoyar proyectos que, muchas veces, los países aislados no pueden llevar a cabo.

En un principio el núcleo de este Consejo era el mundo occidental: Europa, Estados Unidos y Canadá. Con el tiempo se han ido integrando también un gran número de países de América Latina, Africa y Asia. España pertenece al Consejo Internacional de Archivos prácticamente desde sus orígenes y al Comité Ejecutivo desde 1976.

Ya desde el Primer Congreso Internacional de Archivos, que tuvo lugar en París en el año 1950, el C.I.A. ha estudiado y producido una abundante literatura acerca de los llamados archivos económicos. Numerosos inventarios dan testimonio de los resultados obtenidos.

Posteriormente, en 1976, en el Congreso celebrado en Washington se creó el Comité de Archivos de Empresa, como un comité más de los muchos que trabajan en temas específicos dentro del marco del Consejo Internacional de Archivos. Este Comité ha tratado en sus primeras reuniones acerca de la situación de los archivos de empresa en los diferentes países representados. El Comite publica un boletín, Bulletin of the Commitee on Busine Archives, bilingüe en inglés y francés, que es anual y da cuenta de las reuniones anuales del mismo (5). Los trabajos y estudios realizados por el Comité permiten comprobar que si bien hay una gran diferencia entre el panorama que ofrecen países como Alemania, Inglaterra, Bélgica o Francia con el de nuestro país, es verdad que a diferente escala los problemas son los mismos: falta de legislación que apoye una política de salvaguarda de estos archivos y falta también de personal especializado en temas archivísticos en general y de archivos de empresa en particular.

Sin embargo, de un modo general, se puede afirmar que en estos países los archivos del Estado han desempeñado un papel importante marcando las pautas a seguir en las tareas de salvación y conservación de los archivos

(4) Véase Eckhart G. Franz, "Der Internationale Archivrat: Vergangenheit, Gegenwart, Zukunft".

(5) Se han publicado ya cinco números de este boletín, desde el año 1978 al 1982. 
de empresa, acción que a su vez ha estado apoyada y estimulada por iniciativas privadas. Veamos algunos ejemplos:

Alemania, uno de los países que está a la cabeza en temas de archivos económicos, cuenta con una Asociación para la Historia Económica y Social de la que forman parte esencialmente los catedráticos de Historia Social y Económica de la Universidad. Asimismo, desde el año 1976 existe una Asociación para la Historia Empresarial, también dependiente de la Universidad. Pero además, en el sector privado el Deutsche Bank creó en el año 1969 un «Instituto para la investigación de la Historia Bancaria», en cuya dirección hay un Consejo científico al que pertenecen representantes de la Universidad y también de los bancos. Por su parte, los archiveros alemanes están integrados en una Asociación, en cuya sección V se encuentran representados los archiveros económicos y, dentro de éstos, los archiveros bancarios (6). Todas estas entidades han colaborado y apoyado la creación y conservación de archivos económicos y han logrado establecer una importante red de archivos de empresas, de bancos, de archivos en general con fondos para el estudio de la Historia Económica.

Como muestra de la labor ya realizada, se puede citar, por ejemplo, la publicación de un repertorio de archivos económicos alemanes, en el que se indica el lugar de conservación de archivos importantes para la Historia Económica, Social y Técnica. Menciona más de cuatrocientos y calcula que en la República Federal se cuentan más de setecientos depósitos de documentos de estas características (7).

A su vez, el citado Instituto para la investigación de la historia bancaria viene organizado desde el año 1982, anualmente, un coloquio internacional sobre «archivos bancarios e historia de la banca en Europa». El primer coloquio tuvo lugar el 5 de marzo de 1982 en la sede del Instituto, en el Deutsche Bank de Frankfurt. El tema específico fue la «Situación de los archivos bancarios» en los países europeos allí representados, que fueron: por Francia, la Société Générale de París; por Inglatera, el archivero de la Banca Rothschild and Sons Ltd. de Londres; por España, la archivera del Banco de España; por Austria, la representante del Creditanstalt-Bankverein de Viena; por Suiza, el del Schweizerischer Bankverein de Basilea, y por Alemania, el director del Instituto y encargado del archivo del Deutsche Bank de Frankfurt. Hubo además una sesión dedicada a la situación de la investigación sobre Historia de la Banca en estos mismos países.

Este año (1983) el segundo coloquio se ha desarrollado en el mismo lugar y ha tratado acerca de «Las relaciones entre los servicios de documenta-

(6) Véase Manfred PoHL, "Bankarchive in Deutschland".

(7) Véase Ottfried Daschrr, "Les archives économiques en République Fédérale d'Allemagne". 
ción y los archivos». Se presentaron cuatro ponencias por parte de Alemania, Inglaterra, Bélgica y la Suiza alemana. Por lo que se refiere a la situación de la investigación en historia bancaria, este año el tema fue "Los movimientos internacionales de capital en Europa antes de la Primera Guerra Mundial». Las actas del primer coloquio se han publicado ya (8).

En cuanto a Inglaterra, otro de los países realmente avanzados en archivos económicos, se puede afirmar que también han actuado conjuntamente el Estado - autoridades centrales y locales-, empresas privadas y nacionales, bibliotecas y universidades, así como particulares. Como resultado de la acción llevada a cabo por estos organismos, se nombró en 1959 una comisión designada por la Reina y auspiciada por el Primer Ministro, y cuya finalidad, entre otras, era realizar un catálogo de documentos y fondos de archivos antiguos dispersos por el Reino Unido. Como complemento de este Catálogo se ha confeccionado una publicación llamada «Record Repositories in Great Britain», que relaciona por orden alfabético una extensa variedad de organismos donde se encuentran archivos de todo tipo, como, por ejemplo, bibliotecas, institutos, hospitales e institutos médicos, universidades y también empresas privadas.

Por otra parte, el año 1934 se fundó el «Business Archives Council», cuyo objetivo principal era estimular a los empresarios en el sentido de que un buen servicio de archivos sería de un gran valor y rentabilidad para ellos en la buena administración de sus negocios. Su labor ha tenido un éxito notable en el Reino Unido, y entre sus principales realizaciones se encuentran: la confección de un «Survey of Business Records», una serie de publicaciones en este campo, así como cursillos sobre tratamiento de fondos documentales. Puede asegurarse que este organismo ha desempeñado una función decisiva en el desarrollo enorme que los archivos de empresa han adquirido en ese país (9).

Sería largo enumerar aquí los logros conseguidos en este aspecto en otros países europeos. En Francia, desde el año 1945 existe un considerable sector nacionalizado: bancos, seguros, fertocariles, transportes aéreos, electricidad y gas, carbón, etc. A partir de 1949 y como consecuencia de esta política de nacionalizaciones, las empresas estatales fueron obligadas a depositar sus documentos en archivos públicos. En algunos casos la propiedad de los papeles la han seguido conservando las empresas, pero la administración y la asistencia técnica de ellos ha dependido en gran medida de los archiveros del Estado. Hay excepciones, por supuesto, como los bancos, la siderurgia, la química y otras muchas que mantienen sus propios archivos. Pero en cual-

(8) Bankhstorisches Archiv, Europäisches Kolloqium über Bank-Archive und Bankengeschichte am 5 März 1982, Frankfurt am Main.

(9) Raymond P. TonkIN, "Business Archives in the United Kingdom". 
quier caso, la labor llevada a cabo por los archiveros del Estado ha contribuido a impulsar la acción de los empresarios privados, y son ya muchas las empresas que están organizando sus fondos documentales con fines científicos en Francia (10).

\section{Situación de los archivos económicos en España}

En España nos encontramos con una situación bastante diferente. Apenas se ha hecho nada en este sentido hasta épocas muy próximas.

Dos hechos están empezando a cambiar algo el panorama español. Por una parte, el Ministerio de Cultura, a través de la Subdirección General de Archivos y su Centro de Información Documental, está confeccionando desde 1980 un Censo-Guía de los Archivos españoles. En él se recogen datos de todos ellos y en especial de la composición de cada uno, volumen de documentación, estado de conservación que recibe por parte de la entidad productora o propietaria, así como las posibilidades de acceso que ofrece al investigador. Este Censo pone un interés primordial en los archivos con fuentes para la Historia Económica, no sólo en los producidos por organismos estatales, sino también en los de entidades privadas, como bancos y empresas (11).

La recopilación de datos se ha realizado en tres direcciones: en primer lugar, en relación con los fondos de bancos y empresas de gran tradición y envergadura; en segundo lugar, en lo que concierne a archivos de empresas que alcanzaron su mayor dimensión en la época del desarrollo industrial español de los años sesenta, así como de las entidades desaparecidas una vez pasada esa etapa propicia, y finalmente, se han dirigido los esfuerzos a conocer la organización de los archivos administrativos de empresas y bancos de creación reciente.

Los primeros datos globales de algunas de las provincias donde ya se ha realizado el Censo-Guía, en lo que a archivos de bancos y empresas se refiere, son imprecisos aún y todos çoinciden en que sus archivos son de acceso restringido y, en la inmensa mayoría, de utilización exclusiva para el personal de la propia institución. Son muy vagos también los datos que se registran en cuanto a conservación y organización de sus fondos documentales, y todo hace pensar que en la mayoría de los casos los documentos, salvo excepciones, sufren destrucciones indiscriminadas e irremediables, destrucciones que no obedecen, en general, a una política clara de conservación y selección regida por ningún criterio establecido.

(10) Maurice Hamon, "Les archives d'entreprises en France".

(11) Sobre el Censo-Guía de los Archivos españoles, véase Margarita VAzquez dE PARGA, "Panorámica actual de los archivos de bancos y empresas". 
Sin embargo, el mero hecho de la confección de este Censo es ya en sí mismo de una gran importancia para la historia de los archivos en nuestro país. Por una parte, cuando esté concluido, constituirá una aportación muy valiosa para el estudio de los archivos económicos, pues es evidente que para conocer el estado en que éstos se encuentran el primer paso es saber cuántos son y tener recogidos el mayor número de datos acerca de ellos. Por otra parte, la etapa de recogida de datos ha servido ya para que, en muchos casos, los empresarios hayan empezado a tener conciencia de que esa documentación -que tienen acumulada o que destruyen ignorando sus posibilidades de utilización - tiene un valor y un interés, si es tratada adecuadamente, para la investigación científica. Efectivamente, se han producido ya algunos ejemplos, excepcionales por supuesto, de incorporaciones de documentos a algunos archivos históricos provinciales durante la recogida de datos para el Censo (12).

El segundo de los hechos que quizá contribuya a cambiar algo el precario panorama archivístico español, en lo que a fondos de carácter económico se refiere, es la celebración del «Primer Congreso sobre archivos económicos de entidades privadas». Este Congreso, organizado por el Archivo Histórico del Banco de España en el marco de la conmemoración del bicentenario del Banco Nacional de San Carlos, tuvo lugar el 2 de junio de 1982 en la sede central del Banco de España, en Madrid. Tenía como finalidad, además de dar a conocer el citado archivo inaugurando al mismo tiempo su sala de consulta para investigadores, reunir a un grupo destacado de historiadores y archiveros que planteasen la situación de los archivos de algunos bancos y empresas desde el siglo xvi hasta nuestros días. Se trató acerca del estado de conservación, accesibilidad, fondos documentales y cuestiones en general comunes a una serie de archivos hasta ahora en una gran parte desconocidos.

El Congreso se desarrolló en cuatro sesiones de trabajo, siendo de destacar el éxito de público que siguió las sesiones y que llenó por completo la citada sala de investigadores del Archivo del Banco de España, que fue el lugar de la reunión.

Las diferentes ponencias, así como las intervenciones que tuvieron lugar en los coloquios abiertos al final de cada una de las sesiones de trabajo, pusieron de manifiesto, por primera vez en España, la situación generalizada de cierto abandono y olvido en que habian permanecido hasta ahora los archivos de empresas en nuestro país.

(12) Sobre algunos ejemplos de incorporaciones de este tipo, véase la nota publicada en el periódico Sur, de Málaga, de Nicolás Cabranilla, "Archivos privados". 
Las principales conclusiones de este «Primer Congreso sobre archivos económicos de entidades privadas» se podrían resumir así:

1. Que es urgente llamar la atención sobre la importancia de conservar los archivos de las empresas y bancos. En esta tarea deberían colaborar los poderes públicos y también los historiadores económicos, que lo podían hacer a través de la Asociación Española de Historia Económica. Asimismo deberá tenerse en cuenta la opinión de los archiveros y propiciar reuniones de este mismo tipo en las que historiadores $\mathrm{y}$ archiveros puedan intercambiar puntos de vista.

2. Que es importante también llamar la atención de los poderes regionales y provinciales para que se percaten de la importancia de potenciar la conservación, custodia y catalogación de los archivos privados existentes en sus respectivas demarcaciones.

3. Que la tendencia, puesta de manifiesto a lo largo del Congreso, de concentrar archivos privados centralizándolos en determinados núcleos, no significa en absoluto una descapitalización documental de los lugares de origen de la documentación, pues en la situación de nuestros archivos lo importante es que no se pierdan.

4. Por último, llamar la atención de las empresas y entidades productoras sobre el hecho de que nada es ajeno a la atención del historiador; que no existe, en general, documento ni archivo que no resulte interesante para el investigador: del mismo modo que hace cincuenta años los libros de cuentas no tenían interés histórico y sí lo tenían las cartas de políticos de la época, quizá dentro de cincuenta años resulten interesantes para el historiador documentos que hoy no llallan la atención de los investigadores (13).

Como conclusión de este apresurado examen de la situación de nuestros archivos económicos, quizá convendría pedir la colaboración de la Universidad española por medio de sus cátedras de Historia Económica, así como de las de Historia Moderna y Contemporánea, para emprender una verdadera y eficaz política de conservación, descripción y catalogación de los archivos de bancos y empresas, como la que se ha llevado a cabo en otros países. Quizá podría crearse un comité patrocinado por dichas cátedras que, con la ayuda que pudiese prestar el Ministerio de Cultura a través de la Subdirección General de Archivos, constituiría un órgano que contribuyese

(13) Las actas del Primer Congreso sobre archivos económicos de entidades privadas están a punto de publicarse por el Archivo Histórico del Banco de España. 
a mejorar el conocimiento y la posible utilización de estas fuentes primarias de la Historia que son los archivos económicos

\section{BIBLIOGRAFIA CITADA}

BANKhISTORISChES ARChIv, Zeitschrift zur Baudengeschichte. Europäisches Kolloquium über bankarchive und Bankengeschichte, am 5 März 1982, Frankfurt am Main.

Bulletin des ARchives d'EnTREPrises. Bruxelles.

Cabrillana, Nicolás: "Archivos privados", en Sur, 16 noviembre 1982.

Congreso sobre Archivos Económicos de Entidades Privadas, I, Banco de España (3-4 junio 1982). De próxima publicación.

DAscher, Ottfried: "Les archives économiques en République Fédérale d'Allemagne", Bulletin du comité des Archives d'entreprises. Bruxelles, 2 (1979), páginas 23-30.

Franz, Eckhart G.: "Der Internationale Archivrat: Vergangenheit, gegenwart, Zukunft", Archivum XXIX. Londres (1980), pp. 155-173.

Gonzalez Ferrando, José M.": "Los libros de cuentas de la familia Ruiz, mercaderes-banqueros de Medina del Campo (1551-1606)", Congreso sobre archivos económicos de entidades privadas, I, Banco de España (3-4 junio 1982). De próxima publicación.

Hamon, Maurice: "Les archives d'entreprises en France", Bulletin des Archives d'entreprises. Bruxelles, 2 (1979), pp. 15-22.

Heredia Herrera, Antonia: Archivo General de Indias. Inventario de los fondos de Consulados. Madrid, Dirección General de Archivos y Bibliotecas, 1972.

LAPEYRE, Henri: Une famille de marchands: les Ruiz (Contribution à l'étude du commerce entre la France et l'Espagne au temps de Philippe II). SEVPEN, París, 1955.

- "El Archivo Ruiz: veinte años después", en Revista de Occidente. Madrid, número 107, febrero 1972, pp. 160-179.

Madoz, Pascual: Diccionario Geográfico-Estadistico-Histórico de España y sus posesiones de Ultramar, 16 vols. Madrid, 1847.

PoнL, Manfred: "Bankarchive in Deutschland", Bankhitsorisches Archiv. Europäisches Kolloquium über Bankarchive und Bankengeschichte am 5 März 1982. Frankfurt am Main.

ToNkIN, Raymond P.: "Business archives in the United Kingdom", Bulletin du Comité des Archives d'entreprises. Bruxelles, 2 (1979), pp. 7-12.'

VAzquez de PARge, Margarita, "Panorámica actual de los archivos de bancos y empresas", Congreso sobre archivos económicos de entidades privadas, I, Banco de España (3-4 junio 1882). De próxima publicación. 